\title{
Prevalence of Adolescent Prehypertension and Its Correlation with Sleep Duration and Light Condition
}

\author{
Hardaning A. Marantha ${ }^{1}$ \\ Postgraduate Program of Nutrition Science \\ Universitas Sebelas Maret \\ Surakarta, Central Java, Indonesia \\ hardaning.am33@gmail.com
}

\author{
Dono Indarto $^{2}$ \\ Department of Physiology, Faculty of Medicine \\ Universitas Sebelas Maret \\ Surakarta, Central Java, Indonesia \\ donoind323@gmail.com
}

\author{
Lilik R. Kartikasari ${ }^{3}$ \\ Study Program of Animal Husbandry, Faculty of Agriculture \\ Universitas Sebelas Maret \\ Surakarta, Central Java, Indonesia \\ lilik_r_kartikasari@yahoo.com
}

\begin{abstract}
Night sleep duration, lights on and night light exposure can elevate blood pressure in adolescents which lead to prehypertension. Therefore this study aimed to analyse night sleep duration, lights on and night light exposure with prehypertension in adolescents. This cross sectional study recruited 160 students from 6 senior high schools in Surakarta city. Data of night sleep duration, light on and night light exposure were obtained from self-reported questionnaire while blood pressure was measured in the morning visit. Data were analysed using chi-square and logistic regression tests with $p$ value $<0.05$. Prevalence of prehypertension in senior high school students was $26.3 \%$. Selected students had average of night sleep duration $6.82 \pm 1.08$ hours and $47.5 \%$ students slept with lights on and the average of night light exposure among them was $98.93 \pm$ 111.96 lux. Insufficient sleep $(O R=1.048,95 \%$ CI $0.517-2.128$, $\mathrm{p}=0.896)$, lights on $(\mathrm{OR}=1.006,95 \%$ CI $0.497-2.037, \mathrm{p}=0.986)$, and highly night light exposure $(\mathrm{OR}=1.153,95 \%$ CI $0.465-2.859$, $\mathbf{p}=\mathbf{0 . 7 5 9}$ ) were associated with prehypertension in adolescents but it was not statistically significant. After adjusted with sex, BMI for age, and family history of hypertension, night light exposure had the strongest association with prehypertension $(\mathrm{OR}=1.640,95 \% \mathrm{CI}$ 0.541-4.976, $\mathrm{p}=\mathbf{0 . 3 8 2}$ ). High prevalence of prehypertension is found in adolescents of senior high schools in Surakarta city. Night light exposure is associated with prehypertension beside BMI for age, sex, and family history of hypertension. Further investigation is performed to analyze other factors which influence prehypertension in adolescents.
\end{abstract}

\section{Keywords — Prehypertension; blood pressure; adolescent; sleep duration; light condition}

\section{INTRODUCTION}

In the last 10 years, prevalence of global hypertension in all age groups has increased by $5.2 \%$ including children and adolescents in developing countries [1]-[3]. Meanwhile, other studies have documented that prevalence of children prehypertension (6-17 years old) in China increases from $6.38 \%$ to $8.13 \%$ [4] and in India is $3.19 \%$ [5]. According to NkehChungag study performed in South Africa, the prevalence of prehypertension and hypertension in 13-17 years old is $12.3 \%$ and $21.2 \%$ respectively [6]. In the United States, $9.6 \%$ children and adolescent have prehypertension [7]. Based on a study performed in adolescents of senior high schools in Pangkal Pinang, Bangka Belitung, $14.17 \%$ boys and $8.33 \%$ girls have hypertension [8]. Adolescents with prehypertension have 2-3 times higher risk of hypertension in later life compared with adolescents with normal blood pressure [9], [10]. Moreover around $7 \%$ adolescents with prehypertension will annually develop into hypertension [11].

Night sleep duration and night light exposure can affect blood pressure through stimulation of the sympathetic nervous system which leads to hypertension risk in long term period [12]. A study has reported that short night sleep indirectly increases the risk adolescents hypertension through obesity [13]. Two hundred and forty six adolescents with sufficient sleep are more likely to have 0.66 times elevated blood pressure [14]. Furthermore night sleep less than 6.5 increases 2.8 times prehypertension risk [15] and less than 5 hours increases 2.1 times hypertension risk [16].

Beside night sleep duration, lights on during sleep and its exposure indirectly rise blood pressure through disruption of the circadian system and reduction of melatonin secretion. Night shift workers, for instance, were exposed by more intense light at night, had lower level of melatonin compared to the day shift workers $(10.9 \mathrm{ng} / \mathrm{mg}, 95 \%$ CI $3.0-13.6$ vs 15.4 $\mathrm{ng} / \mathrm{mg}, 95 \%$ CI 12.3-19.3) [17]. Gooley et al (2011) have found that up to $50 \%$ reduction of melatonin secretion occurs after less than 200 lux night light exposure for 8 hours [18]. Siegelova's study has emphasized this result that 1-10 unit lux of night light exposure can rises $11 \mathrm{mmHg}$ systolic and 3 $\mathrm{mmHg}$ diastolic blood pressure [19]. Additionally low melatonin levels are positively associated with nitric oxide (NO) production [20] which stimulates the sympathetic nervous system and result in risen blood pressure. Therefore this study aimed to analyse the association of night sleep duration, light on and light exposure with prehypertension in adolescents. 


\section{METHODS}

There were 160 students who participated in this cross sectional study and were selected using stratified random sampling. They aged 15-17 years old and came from 6 senior high schools in Surakarta city. This research protocol was approved by the Ethics Committee of the Faculty of Medicine, Universitas Sebelas Maret/dr Moewardi Hospital, Surakarta with number 352/IV/HREC/2017.

Age, sex and family history of hypertension were determined using self-reported questionnaire. Height was measured using microtoise (SH-2A, GEA Medical) and weight used digital scale (SRF-9332, Serenity). Body Mass Index (BMI) for age was calculated using an anthropometric calculator software (WHO Antro Plus, 2007) then classified into normal, overweight and obese.

Data of night sleep duration, light on, and light exposure were obtained from self-reported questionnaire. Sleep duration was determined using the National Sleep Association [21] and classified into sufficient ( $\geq 7$ hours/night) and insufficient $(<7$ hours/night) sleep. Light condition was classified as light on and off. Light exposure was determined using a formula \{ sleep room lamp power (watt) x luminous efficacy (lm/watt) $\} /$ sleep room area $(\mathrm{m} 2)$ [22] and then classified into low and high exposure based on the average of lights on during sleep.

Blood pressure was measured in the morning using a digital sphygmomanometer (HEM-8712, OMRON Co., Kyoto, Japan) and classified into prehypertension if systolic and/or diastolic blood pressure were $90^{\text {th }}-95^{\text {th }}$ for age, sex, and height, based on The National High Blood Pressure Education Program (NHBPEP) [23], [24].
Collected data were analysed using chi-square tests with $\mathrm{p}$ value of $<0.05$ considered as a statistically significance. Multivariate analysis was conducted using logistic regression test. Numeric data were presented as mean \pm SD and categoric data were in frequency and percentage.

\section{RESULTS}

Table I showed the general characteristics of selected students of senior high schools in Surakarta city. Eighty percent of the students were female and the mean age was 15.89 years old. Overweight and obese status was found in $5.0 \%$ and $14.4 \%$ students, respectively. The average of systolic and diastolic blood pressure was $107.69 \pm 10.30 \mathrm{mmHg}$ and 71.94 $\pm 6.61 \mathrm{mmHg}$, respectively. The prevalence of prehypertension among selected students was $26.3 \%$ and most of them were female. A total of $31.0 \%$ prehypertension students was overweight and obese. Forty two point nine percent prehypertension students had family history of hypertension.

Association between night sleep duration, lights on and light exposure and prehypertension was indicated in Table II. The average of night sleep duration was $6.82 \pm 1.08$ hours and more than $50 \%$ students had sufficient sleep. Compared with insufficient night sleep, normal and prehypertension students had higher sufficient night sleep. Students with insufficient sleep had 1.048 times (95\% CI 0.517-2.128) higher risk of prehypertension compared with students with sufficient sleep although it was not statistically significant $(p=0.896)$.

TABLE I

General CHARACTERISTICS OF 160 StUdENTS IN SENIOR High SCHOOLS IN SURAKARTA City

\begin{tabular}{|c|c|c|c|c|}
\hline & Normal & Prehypertension & $\mathrm{n}(\%)$ & Mean \pm SD \\
\hline & $\mathrm{n}(\%)$ & $\mathrm{n}(\%)$ & & \\
\hline \multicolumn{5}{|l|}{ Sex } \\
\hline Female & $98(83.1)$ & $30(71.4)$ & $128(80.0)$ & \\
\hline Male & $20(16.9)$ & $12(28.6)$ & $32(20.0)$ & \\
\hline Age (years) & & & & $15.89 \pm 0.567$ \\
\hline BMI for age (percentiles) & & & & $52.91 \pm 29.62$ \\
\hline Normal & 100 & $29(69.0)$ & $129(80.6)$ & \\
\hline Overweight & $(84.7)$ & $1(2.4)$ & $8(5.0)$ & \\
\hline Obese & $\begin{array}{r}7(5.9) \\
11(9.3)\end{array}$ & $12(28.6)$ & $23144)$ & \\
\hline \multicolumn{4}{|l|}{ Systolic Blood Pressure $(\mathrm{mmHg})$} & $107.69 \pm 10.30$ \\
\hline \multicolumn{4}{|l|}{ Diastolic Blood Pressure (mmHg) } & $71.94 \pm 6.61$ \\
\hline $\begin{array}{l}\text { Blood Pressure Levels } \\
\text { Normal } \\
\text { Prehypertension }\end{array}$ & & & $\begin{array}{r}118(73.7) \\
42(26.3)\end{array}$ & \\
\hline $\begin{array}{l}\text { Family History of Hypertension } \\
\text { No } \\
\text { Yes }\end{array}$ & $83(70.3)$ & $24(57.1)$ & 107 (66.9) & \\
\hline Yes & $35(29.7)$ & $18(42.9)$ & $53(33.1)$ & \\
\hline
\end{tabular}

There were $47.5 \%$ students who slept with lights on and $26.3 \%$ among them had prehypertension. Light on during night sleep was not associated with prehypertension $(\mathrm{OR}=1.006,95 \% \mathrm{CI}$ 0.497-2.037, $\mathrm{p}=0.986$ ). The average of night light exposure during light on was $98.93 \pm 111.96$ lux. High light exposure was found in $28.6 \%$ students with prehypertension and was associated with prehypertension $(\mathrm{OR}=1.153$, 95\% CI 0.465 $2.859)$, although it was not significant $(\mathrm{p}=0.759)$.
Table III showed the result of multivariate analysis of all research variables adjusted with sex, BMI for age, and family history of hypertension. These variables influenced $9.5 \%$ prevalence of prehypertension in students. The strongest association with prehypertension was observed in BMI for age $(\mathrm{OR}=2.712,95 \%$ CI $1.140-6.447, \mathrm{p}=0.024)$ and followed by sex and family history of hypertension. Among research variables, night light exposure was the strongest association 
with prehypertension $(\mathrm{OR}=1.640,95 \%$ CI $0.541-4.976, \mathrm{p}=0.382)$.

TABLE II

THE AsSOCIATION BETweEn SLEEP DURATION, Lights ON AND Light EXPOSURE AND PREHYPERTENSION AMONG STUDENTS OF SENIOR High SCHOOLS IN SURAKARTA CITY

\begin{tabular}{|c|c|c|c|c|c|c|c|}
\hline & \multicolumn{2}{|c|}{ Normal } & \multicolumn{2}{|c|}{ Prehypertension } & & \multirow{2}{*}{$\mathrm{P}$} & \multirow{2}{*}{$\begin{array}{c}\mathrm{OR} \\
(95 \% \mathrm{CI})\end{array}$} \\
\hline & $\mathrm{n}$ & $\%$ & $\mathrm{n}$ & $\%$ & & & \\
\hline Sleep Duration & & & & & $6.82 \pm 1.08$ & & \\
\hline Adequate ( $\geq 7$ hours) & 66 & 74.2 & 23 & 25.8 & $89(55.6)$ & 0.896 & $1.048(0.517-2.128)$ \\
\hline Inadequate ( $<7$ hours) & 52 & 73.2 & 19 & 26.8 & $71(44.4)$ & & \\
\hline \multicolumn{8}{|l|}{ Light Condition } \\
\hline Off & 62 & 73.8 & 22 & 26.2 & $84(52.5)$ & 0.986 & $1.006(0.497-2.037)$ \\
\hline On & 56 & 73.7 & 20 & 26.3 & $76(47.5)$ & & \\
\hline Light Exposure (lights on) & & & & & $98.93 \pm 111.96$ & & \\
\hline Low $(<98.93$ lux $)$ & 98 & 74.2 & 34 & 25.8 & $132(82.5)$ & 0.759 & $1.153(0.465-2.859)$ \\
\hline High ( $\geq 98.93$ lux) & 20 & 71.4 & 8 & 28.6 & $28(17.5)$ & & \\
\hline
\end{tabular}

TABLE III

Multivariate ANALysis of RESEARCH VARIABLES AdJUSTED WITH BMI FOR AGE, SEX, AND FAMILy HiSTORY OF HyPERTENSION

\begin{tabular}{lcccc}
\hline & B & p & $\begin{array}{c}\text { OR } \\
(95 \% \text { CI })\end{array}$ & $\begin{array}{c}\text { Nagelkerke } \\
\text { R Square } \\
(\%)\end{array}$ \\
\hline BMI for age (overweight and obese) & 0.998 & 0.024 & $2.712(1.140-6.447)$ & 9.5 \\
Sex (Male) & 0.900 & 0.046 & $2.459(1.017-5.943)$ & \\
Family History of Hypertension (Yes) & 0.635 & 0.104 & $1.886(0.878-4.054)$ & \\
Sleep Duration (Inadequate) & -0.210 & 0.588 & $0.810(0.379-1.732)$ & \\
Light Condition (On) & -0.237 & 0.587 & $0.789(0.335-1.858)$ & \\
Light Exposure (High) & 0.495 & 0.382 & $1.640(0.541-4.976)$ & \\
Constant & -1.572 & 0.000 & 0.208 & \\
\hline
\end{tabular}

\section{IV.DISCUSSION}

As described in result section, the prevalence of prehypertension in adolescents in Surakarta city is 26.3\% which female is more dominant than male. However male adolescents have 2.46 times higher risk of prehypertension compared with female adolescents. More than 30\% of prehypertension students is obesity and has family history of hypertension. High light exposure also increases 1.64 times risk of prehypertension in adolescents.

Our results indicate that the prevalence of prehypertension in Surakarta city is higher than other cities in India [5] and South Africa [6]. Obesity and family history of hypertension in our study are the most important risk of adolescent prehypertension compared with overseas studies with only obesity as the main risk factor. However there are few studies that reported the prevalence of adolescents prehypertension. Unfortunately, national prevalence of adolescent prehypertension in Indonesia has not been established. Other studies just reported the prevalence of adolescent hypertension in Indonesia. Of 22.5\% adolescents in Pangkalpinang, Bangka Belitung province have hypertension [8] while $42.5 \%$ adolescents in Surakarta has prehypertension [25]. The high prevalence of prehypertension in Surakarta adolescents is probably caused by not only low physical activity, family history of hypertension, BMI for age, but also night light exposure.
In comparison with other studies, prevalence of prehypertension in female adolescents in our study is higher than male adolescents. Two studies conducted in Jamaica [26] and Surakarta [25] indicate that males adolescents have higher prevalence of hypertension and prehypertension than female adolescents. Perhaps it is caused by the difference of student number and physical activity. Eighty percent students in our study is female adolescents and they have low physical activity (data is not shown). So, further study is required to investigate other factors that contribute in prevalence of prehypertension in female adolescents.

Elevated blood pressure is more common in males than females. According to Shankar et al., 10-17 years are the male puberty age while 8-15 years are the female puberty age. In the earlier gender, systolic blood pressure would increase 3-6 times than that of pre pubertal age [27]. On the other hand, systolic blood pressure in female pubertal age would increase 2-4 times compared with systolic blood pressure in the pre pubertal age [27] and lower than elevated blood pressure in male pubertal age. The possible cause of this different blood pressure is male sexual hormones [28].

Other studies also reported that BMI for age (10-18 years) is positively associated with blood pressure [29] and hypertension [30]. A study involved 93 adolescents found that obese adolescents had higher ambulatory blood pressure and thicker carotid artery intimal-medial thickness (IMT) than non-obese adolescents which it is possibly indicated an early course of obesity-related hypertension [31]. Despite of BMI for age, 
family history of hypertension also increases prehypertension risk in adolescents. Our findings are in accordance with previous studies conducted in Pangkalpinang and Surakarta cities [8], [25]. So the genetic factor may be involved in pathogenesis of prehypertension in adolescents.

In the present study, highly night light exposure increases 1.153 times risk of prehypertension compared with low night light exposure. Another study also documented that night light on increases by $11 \mathrm{mmHg}$ systolic blood pressure in 9 healthy people [19]. Night light exposure can rise blood pressure through disruption of circadian rhythm which result in reduction of melatonin production [17], [18] and nitric oxide (NO) secretion [20]. As a result, it will activate sympathetic nervous system and results in elevation of blood pressure.

Even though we have revealed that BMI for age, sex, family history of hypertension, and light exposure are related to elevated blood pressure, this study has some limitations. In the present study, blood pressure is only measured in one morning visit while The European Society of Hypertension recommends to measure blood pressure on three different occasions [32]. We found that there is no difference in night light exposure between normal and prehypertension adolescents. The night light exposure was only measured using lumen, based on lamp's brand and power, and room size [22]. We did not consider duration of light exposure.

\section{CONCLUSIONS}

High prevalence of prehypertension is found in adolescents of senior high schools in Surakarta city which the important risks of prehypertension are BMI for age, sex, family history of hypertension, and night light exposure. Further studies are needed to investigate other factors which influence prehypertension in adolescents.

\section{ACKNOWLEDGMENT}

We would like to show our gratitude to the headmasters of six senior high schools in Surakarta City for allowing us to conduct this research study. We also thank Prof Bhisma Murti, dr., M.PH., M.Sc. Ph.D., for his guidance in statistical analysis.

\section{REFERENCES}

[1] M. J. Bloch, "Worldwide prevalence of hypertension exceeds 1.3 billion," J. Am. Soc. Hypertens., vol. 10, no. 10, pp. 753-754, Oct. 2016.

[2] K. T. Mills et al., "Global Disparities of Hypertension Prevalence and Control Clinical Perspective: A Systematic Analysis of PopulationBased Studies from 90 Countries," Circulation, vol. 134, no. 6, pp. 441-450, Aug. 2016.

[3] M. M. Ibrahim and A. Damasceno, "Hypertension in developing countries," The Lancet, vol. 380, no. 9841, pp. 611-619, 2012.

[4] Y. Liang et al., "Trends in blood pressure and hypertension among Chinese children and adolescents: China health and nutrition surveys 1991-2004.," Blood Press., vol. 20, no. June 2010, pp. 45-53, 2011.

[5] B. A. Chirag, J. Chavda, K. M. Kakkad, and P. Damor, "A Study of Prevalence of Hypertension in School Children," Gujarat Med. J., vol. 68, no. 2, pp. 79-81, 2013.

[6] B. N. Nkeh-Chungag, A. M. Sekokotla, C. Sewani-Rusike, A. Namugowa, and J. E. Iputo, "Prevalence of hypertension and prehypertension in 13-17 year old adolescents living in Mthatha-South Africa: A cross-sectional study," Cent. Eur. J. Public Health, vol. 23 , no. 1 , pp. 59-64, 2015.
[7] B. Xi et al., "Trends in Elevated Blood Pressure among US Children and Adolescents: 1999-2012," Am. J. Hypertens., vol. 29, no. 2, pp. 217-225, 2016.

[8] M. Yusrizal, D. Indarto, and M. Akhyar, "Risk of Hypertension in Adolescents with Over Nutritional Status in Pangkalpinang, Indonesia," J. Epidemiol. Public Health, vol. 01, no. 01, pp. 27-36, 2016.

[9] K. M. Redwine and S. R. Daniels, "Prehypertension in Adolescents: Risk and Progression: Prehypertension in Adolescents," J. Clin. Hypertens., vol. 14, no. 6, pp. 360-364, Jun. 2012.

[10] K. M. Redwine, A. A. Acosta, T. Poffenbarger, R. J. Portman, and J. Samuels, "Development of Hypertension in Adolescents with PreHypertension," J. Pediatr., vol. 160, no. 1, pp. 98-103, 2012.

[11] B. Xi et al., "Trends in Elevated Blood Pressure Among US Children and Adolescents: 1999-2012," Am. J. Hypertens., vol. 29, no. 2, pp. 217-225, Feb. 2016.

[12] P. Lusardi, A. Zoppi, P. Preti, R. M. Pesce, E. Piazza, and R. Fogari, "Effects of insufficient sleep on blood pressure in hypertensive patients: a 24-h study," Am. J. Hypertens., vol. 12, no. 1, pp. 63-68, 1999.

[13] H. Peach, J. F. Gaultney, and C. L. Reeve, "Sleep Characteristics, Body Mass Index, and Risk for Hypertension in Young Adolescents," $J$. Youth Adolesc., vol. 44, no. 2, pp. 271-284, Feb. 2015.

[14] E. J. Mezick, M. Hall, and K. A. Matthews, "Sleep duration and ambulatory blood pressure in black and white adolescents," Hypertension, vol. 59, no. 3, pp. 747-752, 2012.

[15] S. Javaheri, A. Storfer-Isser, C. L. Rosen, and S. Redline, "Sleep Quality and Elevated Blood Pressure in Adolescents," Circulation, vol. 118 , no. 10, pp. 1034-1040, 2008.

[16] J. E. Gangwisch et al., "Short sleep duration as a risk factor for hypertension: Analyses of the first National Health and Nutrition Examination Survey," Hypertension, vol. 47, no. 5, pp. 833-839, 2006.

[17] K. Papantoniou et al., "Circadian variation of melatonin, light exposure and diurnal preference in day and night shift workers of both sexes," Cancer Epidemiol. Prev. Biomark., vol. 23, no. 7, pp. 1176-1186, Jul. 2014.

[18] J. J. Gooley et al., "Exposure to Room Light before Bedtime Suppresses Melatonin Onset and Shortens Melatonin Duration in Humans," J. Clin. Endocrinol. Metab., vol. 96, no. 3, pp. E463-E472, Mar. 2011.

[19] J. Siegelová et al., "Disturbance of circadian rhythm in blood pressure by lack of darkness at night," Scr. Medica BrNO -, vol. 79, no. 3, pp. 147-154, 2006.

[20] J. Klimentova et al., "Effect of melatonin on blood pressure and nitric oxide generation in rats with metabolic syndrome," Physiol. Res., vol. 65, no. Suppl. 3, pp. S373-S380, 2016.

[21] National Sleep Foundation, "National Sleep Foundation Recommends New Sleep Times," National Sleep Foundation, 02-Feb-2015. [Online]. Available: https://sleepfoundation.org/press-release/national-sleepfoundation-recommends-new-sleep-times/page/0/1. [Accessed: 01Dec-2017].

[22] R. F. Haghlun, Springer Handbook of Lasers and Optics, 2nd ed. Berlin, Springer Science \& Business Media, 2012.

[23] National High Blood Pressure Education Program, "The Fourth Report on The Treatment of High Blood Pressure in Children and Adolescents," National Institute of Health National Heart, Lung, and Blood Institute, 05-5267, May 2005.

[24] B. Falkner and S. R. Daniels, "Summary of the Fourth Report on the Diagnosis, Evaluation, and Treatment of High Blood Pressure in Children and Adolescents," Hypertension, vol. 44, no. 4, pp. 387-388, Oct. 2004.

[25] R. C. Puspita, D. Gunawan, and D. Indarto, "Implementation of Health Belief Model for the Analysis of Factors Affecting Hypertension Preventive Behaviors among Adolescents in Surakarta," Tesis, Universitas Sebelas Maret, Surakarta, 2017.

[26] T. S. Ferguson et al., "Prevalence of prehypertension and its relationship to risk factors for cardiovascular disease in Jamaica: Analysis from a cross-sectional survey", BMC Cardiovasc. Disord., vol 8, no. 20, 2008.

[27] R. Ravi Shankar, George J. Eckert, Chandan Saha, Wanzhu Tu, and J Howard Pratt, "The Change in Blood Pressure during Pubertal Growth," J. Clin. Endocrinol. Metab., vol. 90, no. 1, pp. 163-167, Jan. 2005 . 
[28] D. R. Ewald and L. A. Haldeman, "Risk Factors in Adolescent Hypertension.," Glob. Pediatr. Health, vol. 3, pp. 1-26, 2016.

[29] V. K. Moselakgomo, A. L. Toriola, B. S. Shaw, D. T. Goon, and O. Akinyemi, "Body mass index, overweight, and blood pressure among adolescent schoolchildren in Limpopo province, South Africa," Rev. Paul. Pediatr., vol. 30, no. 4, pp. 562-569, 2012.

[30] S. Arora, S. Gupta, and P. Singh, "Assessment of risk factors for hypertension and obesity among adolescents," Sri Lanka J. Child Health, vol. 46, no. 1, p. 48, Mar. 2017.
[31] S. Stabouli, V. Kotsis, C. Papamichael, A. Constantopoulos, and N. Zakopoulos, "Adolescent Obesity is Associated with High Ambulatory Blood Pressure and Increased Carotid Intimal-Medial Thickness," $J$. Pediatr., vol. 147, no. 5, pp. 651-656, Nov. 2005.

[32] E. Lurbe et al., "2016 European Society of Hypertension guidelines for the management of high blood pressure in children and adolescents," $J$. Hypertens., vol. 34, no. 10, pp. 1887-1920, Oct. 2016. 